DOI 10.37882/2223-2982.2021.12.09

\title{
ГЕНДЕРНЫЙ АСПЕКТ ФУНКЦИОНИРОВАНИЯ НЕОСЕМАНТОВ НИЩЕБРОД И НИЩЕБРОДКА В НЕФОРМАЛЬНОЙ ИНТЕРНЕТ-КОММУНИКАЦИИ
}

\section{GENDER ASPECT OF FUNCTIONING OF THE NEOSEMANTS NISHCHEBROD AND NISHCHEBRODKA IN INFORMAL INTERNET COMMUNICATION}

E Kallistratidis

Summary: The article regards neosemants "nishchebrod" and "nishchebrodka" and their functioning specifics in the Russian informal internet-communication. The quantitative analysis shows the tendency towards their using in users' speech for evaluative characterizing a person as a participant of romantic or family relationship. The article also registers that their functioning is determined by the newer alterations of gender beliefs and by the transformations of axiological directions of the media active Russian language speakers.

Keywords: informal Internet communication, gendered discourse, gendered speech, neosemantization.
Каллистратидис Евгения Владимировна к.филол.н., доцент, Южный федеральный университет, Ростов-на-Дону evakallas@sfedu.ru

Аннотация: Рассматриваются особенности функционирования неосемантов «нищеброд» и «нищебродка» в неформальной интернет-коммуникации на русском языке. С помощью количественных методов выявляется тенденция к употреблению этих единиц в гендеризированной речи пользователей для оценочной характеристики лица как участника романтических и семейных отношений. Устанавливается обусловленность их функционирования новейшими изменениями гендерных представлений и трансформациями ценностных ориентаций медийно активных носителей русского языка.

Ключевые слова: неформальная интернет-коммуникация, гендерный дискурс, гендеризированная речь, неосемантизация.
A ктуальность настоящего исследования обусловлена необходимостью научного осмысления неформального гендерного интернет-дискурса, который представляет собой комплексное динамически развивающееся и постоянно пополняющееся множество интернет-текстов, различных по своей природе, жанровой принадлежности и вербальному оформлению и характеризующихся гендерной тематикой и проблематикой или же имеющих имплицитные гендерно значимые смыслы. Коммуникативное киберпространство становится новой сферой существования, актуализации, ретрансляции и трансформации гендерных представлений, сферой, не менее важной, чем традиционные медиа, но при этом открывающей практически неограниченный доступ не только к медиатекстам профессиональных коммуникантов, но и к повседневным речевым практикам рядовых носителей языка - обычных мужчин и женщин, осмысляющих гендерные отношения, обсуждающих полоролевые установки и стереотипы, а также вступающих в виртуальные гомогендерные социальные объединения. Эти речевые практики становятся неотъемлемой частью повседневной жизни многих русскоговорящих, а ведь именно человеческая повседневность, по мнению R. W. Connell, является главной «ареной гендерной политики» $[12$, c. 3]. Для русскоязычной неформальной интернеткоммуникации характерны следующие черты: установка на отказ от традиционной социальной иерархии, искрен- ность коммуникации, свобода самовыражения и коммуникативного поведения, высокий уровень метаязыковой рефлексии, а также осознанное творческое отношение к языковой материи. Эти особенности, а также социально, экономически и психологически обусловленная потребность говорящих в новых номинациях способствуют появлению в интернет-текстах значительного количества нестандартных средств репрезентации категорий фемининности и маскулинности: лексических заимствований, словообразовательных инноваций, игровых трансформ и неосементов, - при этом многие из них употребляются регулярно и, входя в узус интернет-опосредованного общения, могут способствовать вербализации отдельных фрагментов гендерной картины мира. Выявление особенностей употребления неосемантов нищеброд и нищебродка в составе гендеризированных интернет-текстов, установление реализуемых ими функций и характеристика наиболее типичных ситуаций их использования поможет внести некоторый вклад в исследование современных представлений носителей русского языка о гендерном порядке и, в частности, о ролевой модели «мужчина - кормилец (добытчик), женщина - хранительница очага».

Лексема нищеброд, как заключает Т.А. Жданова, опираясь на данные национального корпуса русского языка, была наиболее распространена в начале XX в., а 
затем практически не использовалась вплоть до 1970 1980-х гг., вслед за этим последовал очередной период забвения, но уже в 2000-е годы её снова начинают активно употреблять «преимущественно в публицистическом стиле, интернет-общении, молодежном сленге» [3, с. 616-617]. Исследователь рассматривает слово нищеброд не просто как лексическую единицу, но как этноспецифический концепт субъективной природы, имеющий на современном этапе развития языка следующие признаки: нищеброд - это «человек, который не имеет денег. <...> Стремится казаться тем, кем не является». $<$...> Он недостаточно умен. <...> Может украсть. <...> Имеет низкое социальное положение. <...> Неудачник. $<$...> Не пытается изменить жизнь к лучшему. <...> Выражает презрительное отношение богатых к бедным» [3, с. 617-618]. Отмечается, что, даже претерпевая изменения, концепт сохраняет смысловой компонент «бедность», а в его основе лежат оппозиции «богатый - бедный», «умный - глупый», «успешный - неуспешный», при этом в современных повседневных речевых практиках (в частности - в интернет-коммуникации) для лексемы характерна резко негативная оценочность [3, с. 618]. В.В. Посиделова относит указанную единицу к разряду «инвектив, описывающих инвектума с точки зрения финансового статуса» [7, с. 15]. Н.Г. Бабенко и Н.Е. Лихина, рассматривая функционально-семантическую специфику слова нищеброд, разделяют его «изначальное» и «современное» значения и доказывают, что последнее является результатом «семантической деривации как разновидности вторичной номинации» [1, с. 23]. Исследователи считают, что его неосемантизация обусловлена целым рядом экстралингвистических факторов, включающих в себя «социально-экономические, психологические и культурные условия существования российского социума в первые десятилетия XXI века» [1, с. 23]. Опираясь на анализ обширного материала интернет-коммуникации, ученыё показывают, что забытое ранее слово нищеброд в своем новом «неканоническом» употреблении «оказалось востребованным как номинация социального типажа» [1, с. 26]. М.А. Секерина указывает на тот факт, что единица нищеброд является характерной для так называемого «женского патриархального дискурса», «акторы которого отстаивают патриархальные семейные роли и ценности, отвергая иные варианты гендерной самоидентификации» $[9$, с. 140].

Согласно нашим наблюдениям, рассматриваемая лексема и её дериваты регулярно употребляются в различных интернет-текстах гендерной тематики и широко используются в составе высказываний, продуцентами которых являются не только женщины, но и мужчины. С целью доказательства этого предположения мы проводим количественный анализ контекстов употребления неосемантов нищеброд и нищебродка, полученных методом сплошной выборки в ходе непосредственного наблюдения за процессом неформального интер- нет-общения, а также с помощью поискового ресурса Google и встроенных поисковых систем социальной сети ВКонтакте и видеохостинга Youtube. При сборе эмпирического материала предпочтение отдавалось текстам неинституциональной интернет-коммуникации, исключались повторяющиеся посты, высказывания на украинском языке, классические художественные произведения, а также интернет-публикации официальных СМИ. В результате в авторскую картотеку было включено 2850 контекстов объемом от 5 до 1500 слов, размещённых в русскоязычном сегменте сети Интернет в период с 2007 по сентябрь 2021 гг. Отбор элементов картотеки, соответствующих параметрам «тематика высказывания» и «заявленный пол продуцента», а также дальнейшие расчеты проводятся вручную. Определение семантики указанных единиц и выявление их функций в составе конкретных высказываний производится с помощью методов компонентного, контекстуального и дискурсивного анализа.

Количественное исследование интернет-текстов, вошедших в авторскую картотеку, позволило получить следующие результаты. Из 1864 зафиксированных нами контекстов употребления неосеманта нищеброд 224 высказывания (12\%) относятся к политическому дискурсу, в 813 случаях (43,6 \%) присутствует социальная критика (при этом продуценты могут как описывать конкретные события повседневности, так и в целом рассуждать о существующем порядке вещей, осмыслять и осуждать наблюдаемые ими закономерности социальной жизни), 827 контекстов по своей тематике относятся к гендерному дискурсу (44,4 \%). В последнем случае неосемант используется для характеристики и негативной оценки конкретного мужчины и/или определенного типа мужчин (604 контекста, 73 \%), в качестве самообозначения при отнесении продуцентом самого себя к классу мужчиннищебродов (41 контекст, 5 \%), также рассматриваемая лексема, становясь объектом эксплицитной метаязыковой рефлексии, входит в состав метаязыковых высказываний (182 контекста, 22 \%). Употребление неосеманта в составе гендерно значимых высказываний в большей степени характерно для коммуникантов женского пола: в 529 случаях (64 \%) продуцентом высказывания является женщина (или пользователь, позиционирующий себя как женщина), в 281 (34 \%) - мужчина (или коммуникант с мужской самоидентификацией), установить гендерную принадлежность авторов 17 высказываний (2 \%) не представляется возможным. Единица нищебродка присутствует в составе 986 контекстов, из них только 36 (4 \%) относится к политическому дискурсу, в 255 (26 \%) содержится социальная критика, 695 высказываний (70 \%) являются гендерно значимыми. Использование единицы нищебродка в составе гендеризированных высказываний свойственно как мужчинам, так и женщинам, однако в мужских репликах оно встречается значительно чаще: 522 контекста (75 \%) и 159 (23\%) соответственно, 
при этом в 14 случаях (2 \%) пол коммуниканта установить невозможно. Лексема используется в первую очередь для экспликации негативной оценки лица женского пола (927 высказываний, 94 \%) и значительно реже как средство самообозначения (27 контекстов, 2,8 \%) и объект метаязыкового осмысления и оценки (32 контекста, 3,2 \%). Необходимо отметить и то, что в качестве основания для негативной оценки мужчинами и женщинами указываются разные причины. Коммуниканты мужского пола называют нищебродками не только женщин, чей уровень достатка не соответствуют определенным требованиям, но и тех, кто требует финансовых вложений от своих партнеров, рассматривает возлюбленного как источник заработка, в то время как пользовательницы регулярно употребляют лексему для обозначения своих реальных или воображаемых соперниц, характеризуя их внешность, одежду, отказ от практик красоты (выглядит как нищебродка, одета как нищебродка и т.п.). Анализ картотеки также помогает установить временные периоды активного употребления единиц нищеброд и нищебродка. Так, чуть менее половины отобранных высказываний (1305 контекстов, 45,8\% картотеки) датируется 2021 годом. Безусловно, это объясняется возможностями поиска Вконтакте и Youtube, выдающего только наиболее релевантные публикации. Анализ высказываний, отобранных с помощью поискового сервиса Google при ограничении временного периода датировки искомых текстов (с 01.01.2007 по 31.12.2007, с 01.01.2008 по 31.12.2008 и так далее вплоть до 30.09.2021), позволяет сделать вывод о стабильном увеличении количества употреблений рассматриваемых неосемантов и существенном росте в периоды экономического кризиса, при этом рост наблюдается не в момент фиксируемого в СМИ ухудшения экономической ситуации, а спустя один или два года. Так, Google обнаруживает 15 контекстов единицы нищеброд в 2007 г., 16 в 2008 г., 44 в 2009 г., а уже в 2010 г. - 117 контекстов. Необходимо отметить и то, что лексема далеко не сразу начинает использоваться в гендеризированной речи, процент гендерно значимых высказываний увеличивается со временем: если в 2007 - 2009 гг. это единичные контексты, то уже в 2010 г. они составляют $9 \%$ от всех употреблений неосеманта, в 2011 г. - 29 \%, затем следует постепенный рост, пик которого приходится на ознаменовавшийся экономическим и социальным кризисом 2020 г. - $49 \%$. Что касается единицы нищебродка, то она начинает использоваться в неформальной интернет-коммуникации позднее, однако так же в период ухудшения экономической ситуации. Первые содержащие ее высказывания датируются 2009 - 2010 гг., в дальнейшем количество употреблений стабильно растет, при этом абсолютное большинство ранних контекстов являются гендерно значимыми (100\% в 2009 г., 80 \% в 2010 г.), в них единица используется для обозначения меркантильной женщины, ищущей выгоды в романтических отношениях, а также для указания на потенциальную партнершу, чей социальный статус и уровень благосостояния не соответствуют ожиданиям продуцента. Со временем лексема нищебродка все чаще встречается в контекстах социальной критики, при описании событий повседневной жизни, а также для самообозначения в сообщениях о временных финансовых затруднениях, тем не менее процент гендеризированных высказываний остается достаточно высоким: 62,5\% в 2011 г., 86\% в 2012 г., 52\% в 2013 г., 71\% в 2014 г., 70\% в 2015 г., 57\% в 2016 г., 54\% в 2017 г., 48\% в 2018 г., 61\% в 2019 г., 64\% в 2020 г.

Важнейшими функциями, реализуемыми неосемантом нищеброд в составе гендеризированных высказываний неформальной интернет-коммуникации, являются номинативная и идеологическая. Единица регулярно используется для обозначения потенциального (или реального) партнера, не соответствующего требованиям продуцента, и при этом способствует вербализации и ретрансляции традиционного стереотипа, согласно которому мужчина должен быть финансово состоятельным и обеспечивать свою партнершу. С этими двумя функциями тесно связана экспликация негативной оценки. Необходимо отметить, что продуцентами 88 \% контекстов негативной оценочности являются женщины и только 12 \% - мужчины. Пользовательницы выражают отрицательное отношение к конкретному лицу мужского пола и/ или определенному типу мужчин, при этом в целом ряде контекстов характеризуется как отдельный человек (зачастую близкий: супруг, жених и т.д.), так и целый класс, к которому продуцент относит обозначаемое лицо. Неосемант нередко используется вместе с другими единицами, выражающими негативную оценку, дополняет их или дополняется ими, например: У нас есть нормальные парни, которые зарабатывают хотя бы 50к? Или одни нищеброды в Череме? Где их искать вообще? Одни жлобы и нищие попадаются (21.09.2021) [5] (здесь и далее орфография и пунктуация сохранены - Е.К.); Пополамщик в 100 прочентах случаев из 100 обычный нищеброд, с непонятным источником ... Пополамщик это жлоб потенциальный альфонс халявщик (11.01.2020) [8]; Она красивая неглупая девчонка, зачем ей этот нищебродсодержанец (02.10.2021) [2]; По статистике если папка нищеброд то в 65\% сын такого же уровня заработка. ... если вы голодранеи, не создавайте детей (11.11.2019) [14]. Это могут быть как стандартные лексемы (голодранеи, жмот, жлоб, альфонс), так и распространенные в неформальном интернет-опосредованном общении единицы (инновация пополамщик, неосемант содержанец), в семантике которых присутствуют (или ситуативно актуализируются) компоненты «деньги», «финансовое положение», указание на мужской пол обозначаемого лица и негативная оценка. Нищебродам пользовательницы противопоставляют нормальных парней, нормальных (настоящих, достойных, адекватных) мужчин (мужиков). С эмоционально-оценочной функцией единицы нищеброд тесно связана другая ее функция - категоризации дей- 
ствительности. Неосемант регулярно используется для обозначения определенного типа, класса мужчин и часто встречается в ориентированных на женскую аудиторию интернет-публикациях, имеющих подобные заголовки: Классификация типов мужчин (14.10.2019) [13]; Сколько должен зарабатывать мужик в России - 7 типов мужчин по уровню дохода (30.07.2021) [16]. В таких публикациях содержатся советы и рекомендации по выбору спутника жизни и приводятся перечни мужских типажей, которых читательницам следует избегать. Нередко встречаются статьи, полностью посвященные конкретному типу мужчин: Tun мужчины нищеброд-собственник. Что делать, если ты сильна? (27.07.2020) [15]; Может ли нищеброд стать достойным мужчиной? [11]. Рассматриваемая единица часто встречается в составе заголовков блогпостов, наименований тредов форумов, а также названий разного рода видеороликов. В самих материалах эксплуатируется традиционный для патриархатной культуры эталонный образ мужчины-добытчика, мужчины-кормильца, при этом несоответствие идеализированному стандарту стигматизируется и получает специфическое вербальное обозначение (нищеброд, пополамщик, альфонс, содержанец и т.д.). Как правило, такие публикации размещаются в блогах и пабликах, рассчитанных на женскую аудиторию, а затем распространяются посредством социальных медиа, они также появляются на персональных сайтах и страницах пользователей (как женщин, так и мужчин), заявляющих о себе как о психологах, коучах или тренерах личностного роста и ведущих в Сети коммерческую деятельность. Типичным является следующий текст: Давай честно! Я знаю, что на этапе конфетнобукетного периода, в отношениях мужчина кажется полубогом. Потом страсти утихают, ты оглядываешься и видишь где-то за спиной его - недогоняющего нищеброда. Он ждет, когда ты придешь с работы, (У таких женшина должна работать. Без вариантов.), сходишь в супермаркет, нажаришь картошечки, приготовишь ванну... [11]. В данном случае неосемант нищеброд наряду с другими речевыми средствами (эмоционально окрашенными лексемами, разговорными речевыми оборотами) способствует созданию непринужденной атмосферы общения, помогает привлечь внимание потенциальной клиентки, которая может решить, что психолог говорит с ней на одном языке, понимает ее потребности, разделяет ценности, и, как результат, приобрести услугу, тренинг или курс лекций. Единица также часто встречается в составе текстов женских объявлений на сайтах знакомств и постов в специализированных (посвященных знакомствам) группах и пабликах в социальных сетях. Пользовательницы употребляют ее для того, чтобы облегчить поиск потенциального партнера, очертить круг желаемых претендентов, при этом нередко их тексты выглядят двусмысленно, например: Ищу парня, красивого, обеспеченного. Минимум в месяц от 30к на моё содержание. Нищеброды на жиге мимо, я знаю себе цену, пупсики) (07.09.2021) [4]. Вполне вероятно, подобная неоднознач- ность создается осознанно, в этом случае рассматриваемая единица способствует установлению контакта, поскольку помогает в завуалированной форме передать смысл, вызывающий общественное порицание. Обычно неосемант используется в конце текста объявления в составе устойчивых, регулярно воспроизводящихся сочетаний: нищеброды мимо, нищебродам не писать, нищебродам не беспокоить. В текстах мужских объявлений неосемант регулярно используется в качестве самообозначения и, по всей видимости, также помогает очертить круг потенциальных знакомств. С помощью такого средства саморепрезентации мужчина дает понять потенциальным собеседницам, что он не заинтересован в отношениях с меркантильными женщинами и не занимается поиском специфических услуг на сайте знакомств. В социальных сетях даже появляются тематические паблики, в названии которых используется рассматриваемая единица: Знакомства для лохов и нищебродов, Знакомства для нищебродов, Знакомства для нищебродов и аутистов в Минске. Здесь неосемант выполняет парольную функцию и способствует установлению контакта между потенциальными собеседниками и собеседницами, имеющими схожие цели и ценностные установки, рассматривающими романтические отношения вне категорий богатства, успешности и т.д.

Неосемант входит в состав слов-композитов в качестве второго компонента, где первая составляющая общеупотребительная лексема с ядерной семой «лицо мужского пола» (мужик-нищеброд, мужчина-нищеброд), в том числе и узуальная единица, указывающая на мужские семейные роли (муж-нищеброд, отец-нищеброд, папа-нищеброд). Единица имеет целый ряд дериватов (нищебродный, нищебродский, нищебродничать, нищебродить, нищебродствовать, нищебродство) и несколько игровых трансформ (днищеброд, нижеброд), при этом все они регулярно встречаются в составе гендерно значимых высказываний и способствуют номинации, категоризации и оценке лиц мужского пола, а также их действий и особенностей поведения. Согласно нашим наблюдениям, изо всех дериватов рассматриваемой единицы чаще всего в неформальном интернет-общении встречается феминитив нищебродка. В Сети он появляется немного позже, чем исходная лексема, при этом тексты, в которых он используется зачастую создаются мужчинами и представляют собой пародию на женские объявления, размещаемые на сайтах знакомств, например: Познакомлюсь с женщиной для серьезных отношений. О себе: не работаю, есть двое детишек. <...> Требования: доход свыше 150к, наличие собственного авто и жилплощади, рост от 172, вес не более 55 кг, без детей. Нищебродок и озабоченных БОЛЬШАЯ ПРОСЬБА не беспокоить (08.09.2021) [6]. В подобных шутливых речевых произведениях высмеиваются завышенные требования женщин, а также их собственная экономическая беспомощность, в саркастической форме выражается неже- 
лание содержать взрослого дееспособного человека. В комментариях к таким публикациям нередко подчеркивается несправедливость ретранслируемых пользовательницами полоролевых стереотипов, их неадекватность актуальной социально-экономической ситуации, а также несоответствие самих девушек традиционному эталону хорошей жены. В текстах мужчин, называющих нищебродками меркантильных и финансово несостоятельных женщин, часто вербализируются представления о гендерном контракте «работающего взрослого», который противопоставляется патриархатной модели «мужчина - кормилец (добытчик), женщина - хранительница домашнего очага». В целом ряде мужских высказываний подчеркивается, что социальный статус партнерши и ее финансовое благополучие являются обязательными критериями при выборе спутницы жизни, при этом контекст употребления единицы нищебродка не позволяет сделать однозначный вывод о шутливом, пародийном характере содержащего ее речевого произведения. Как и исходная единица, феминитив используется для выражения негативной оценки, которая присутствует в 94 \% включенных в картотеку контекстов, и при этом регулярно дополняется другими оценочными лексемами, как это происходит в следующем высказывании: Крик души. Перевелись «настоящие женщины». Создавать семью не с кем. Вокруг одни пустожорки, халявщицы, принцеждалки, разведёнки, овуляшки, яжмамки, нищебродки, не в состоянии даже за себя заплатить на свидании (07.09.2021) [10]. Однако в отличие от неосеманта нищеброд феминитив не способствует реализации ни парольной, ни фатической функции; по всей видимости, это связано с тем, что даже в современном российском обществе уровень достатка не представляется обязательной характеристикой женщины как потенциальной участницы романтических или семейных отношений. При поиске партнера пользовательницы не считают нужным оговаривать свое скромное положение и, ожидая финансовой помощи от возможного поклонника, предпочитают обозначать свои потребности с помощью других вербальных средств, без оправданий и самоуничижения. Важно отметить и то, что вне гендерного дискурса в качестве самообозначения женщины значительно чаще используют единицу нищеброд, функционирующую как слово общего рода, в то время как феминитив нищебродка преимущественно встречается в составе гендеризированных высказываний, при этом он употребляется мужчинами для указания на лицо женского пола, а также женщинами для обозначения других женщин и крайне редко в качестве средства самономинации и саморепрезентации.

Таким образом, неосемант нищеброд регулярно употребляется в составе гендерно значимых речевых произведений неформальной интернет-коммуникации, выполняя в них целый ряд взаимосвязанных функций: номинативную, идеологическую, оценочную, фатическую, парольную, а также функцию категоризации действительности. Феминитив нищебродка оказывается вторичным по отношению к исходной единице (как в словообразовательном отношении, так и с точки зрения специфики функционирования) и в связи с этим обладает ограниченным функционалом. Лексема нищеброд имеет некоторые признаки ключевого слова текущего момента: занимает сильную позицию в тексте, входя в состав заголовочных комплексов, подзаголовков, а также завершающих речевое произведение высказываний, образует целый ряд активно функционирующих дериватов и становится объектом языковой игры и метаязыковой рефлексии, - все это позволяет сделать вывод о том, что эта единица, некогда вышедшая из употребления и еще совсем недавно казавшаяся устаревшей, в настоящее время относится к разряду актуальной лексики гендерного интернет-дискурса. Мы предполагаем, что узус неформальной интернет-коммуникации является в некотором роде отражением разговорных речевых практик, не опосредованных новейшими каналами связи, и неосеманты нищеброд и нищебродка активно употребляются не только в Рунете, но и в повседневной речи, в том числе и при обсуждении отношений между мужчинами и женщинами, характеристике потенциальных партнеров и осмыслении гендерных ролей в семье и в социуме. Рассматриваемые лексемы обладают значительным конфликтогенным потенциалом, так как они способствуют созданию и распространению негативных обобщенных образов маскулинности и фемининности. Последовательная и регулярная категоризация, номинация и негативная оценка лиц мужского пола в текстах, потенциально доступных неограниченной аудитории, является одним из проявлений токсичной фемининности и провоцирует появление аналогичных вербальных действий в отношении лиц женского пола. Возникновение и систематическое использование лексем, относящихся одновременно к семантическим сферам «финансы», «семья» и «любовь» свидетельствует о существенных трансформациях ценностных представлений носителей русского языка.

\section{ЛИТЕРАТУРА}

1. Бабенко Н.Г., Лихина Н.Е. Неосемантизация слова нищеброд в современной русской речи // Научный диалог. 2019. № 11. С. 23-33. D0I: 10.24224/22271295-2019-11-23-33.

2. Дом2 Уже Всемогущий. Фото. Новости. Ретро. Режим доступа: https://vk.com/wall-3765873_25945121 (дата обращения: 08.11.2021). 
3. Жданова Т.А. Концепт нищеброд в наивном сознании русского народа // Когнитивные исследования языка. 2020. № 3 (42). С. 615-619.

4. Знакомства Нижний Новгород Бор Дзержинск Кстово. Режим доступа: https://vk.com/nnlovenn (дата обращения: 08.11.2021).

5. Подслушано Черемхово NEW. Режим доступа: https://vk.com/podslushano_cheremhovo (дата обращения: 08.11.2021).

6. Подскажи Северодвинск. Режим доступа: https://vk.com/club135803348 (дата обращения: 08.11.2021).

7. Посиделова В.В. Лингвистический и правовой аспекты инвективной лексики русского языка // Философия права. 2016. № 2 (75). С. 13-17.

8. Психология для всех. Режим доступа: https://zen.yandex.ru/media/psy/kto-takie-popalamsciki-i-pochemu-ih-stoit-osteregatsia-5e1893ce9c944600ad9645b0 (дата обращения: 08.11.2021).

9. Секерина М.А. Дискурсивно-прагматические функции неологизмов (на материале персонального интернет-дискурса) // Русский язык на перекрёстке эпох: традиции и инновации в русистике. - Ереван: Изд-во РАУ, 2018. 482 с. С. 134-142.

10. Сплетни города Валуйки. Режим доступа: https://vk.com/valuiky (дата обращения: 08.11.2021).

11. Ярослав Самойлов. Режим доступа: https://yaroslav-samoylov.com/psihologija-otnoshenij/mozhet-li-nishhebrod-stat-normalnym-muzhchinoj.html (дата обращения: 08.11.2021).

12. Connell R. W. Masculinities. Berkley, Los Angeles: University of California Press, 2005. 324 p.

13. Mila Sadowskaya. Режим доступа: https://www.sadowskaya.com/single-post/2019/10/14/классификация-типов-мужчин (дата 0бращения: 08.11.2021).

14. Pikabu. Режим доступа: https://pikabu.ru/story/papa_tyi_neudachnik_7039234 (дата обращения: 08.11.2021).

15. рroГендер. Режим доступа: https://zen.yandex.ru/media/dating/tip-mujchiny-niscebrodsobstvennik-chto-delat-esli-ty-silna-5f19cca0cadd342070693099 (дата обращения: 08.11.2021).

16. SEIV.IO Режим доступа: https://seiv.io/skolko-doljen-zarabotat-mujik.html (дата обращения: 08.11.2021).

( К Каллистратидис Евгения Владимировна (evakallas@sfedu.ru).

Журнал «Современная наука: актуальные проблемы теории и практики»

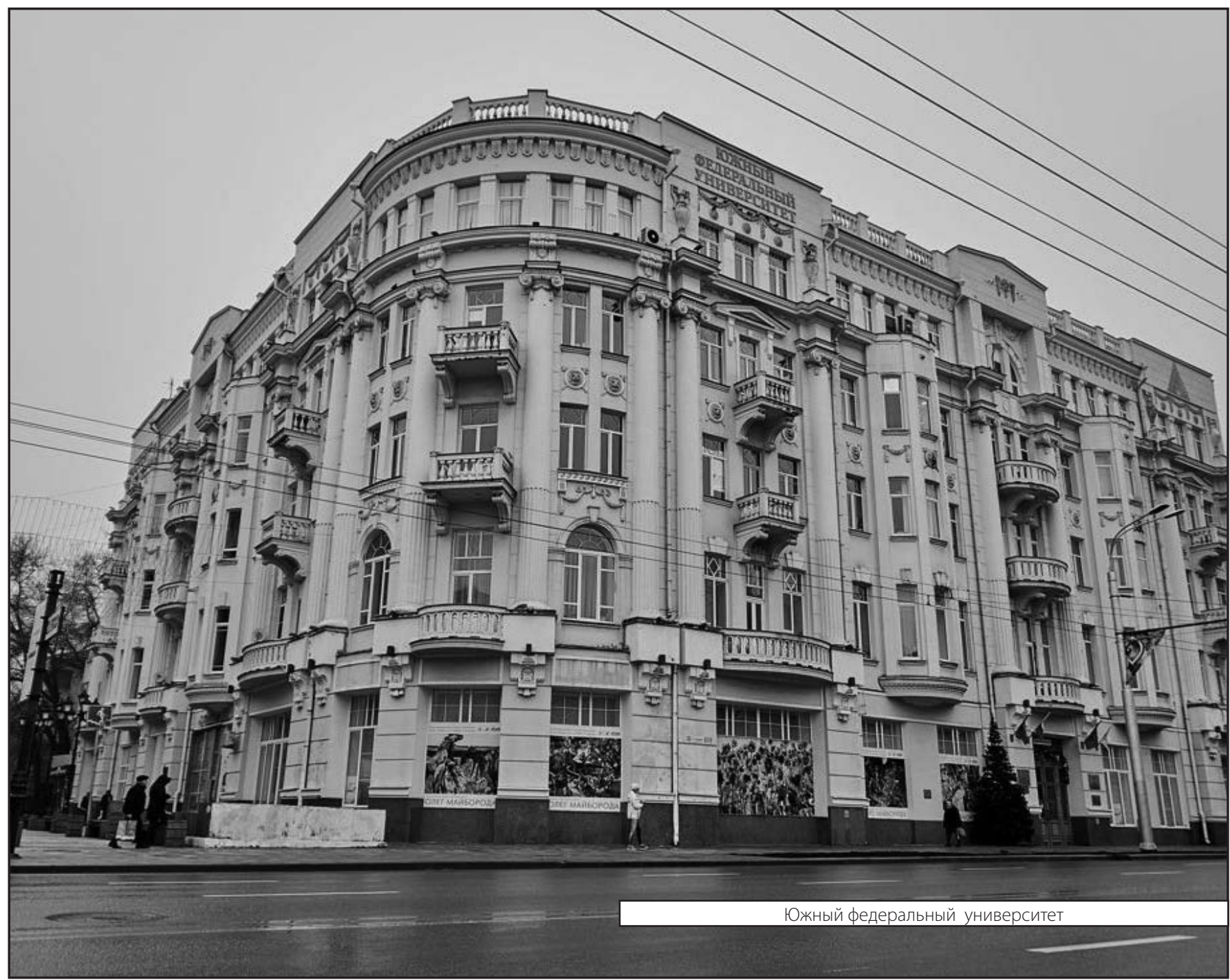

